\title{
Script as a Factor in Translation
}

\author{
Judy Wakabayashi \\ Kent State University \\ jwakabay@kent.edu
}

\begin{abstract}
Translators usually pay little or no heed to the script embodying the meaning of a text, yet at times the script itself makes a significant contribution to a text's meaning, aesthetics or ideology, for instance. In such cases translators need to consider the writer's orthographical choices, as well as if and how these can or should be reflected in the target text. This presents particular challenges when the two languages use different scripts. With its four scripts, Japanese offers an emblematic instance of the role of script in writing and translation. Focusing on this striking case can raise awareness of instances where script plays a role even in alphabetic languages, although to a lesser degree, and it also suggests some techniques that can be used for handling script issues in translation.
\end{abstract}

\section{Keywords}

script - translation - Japanese - orthography

\section{Introduction}

Alongside its communicative and social functions, written translation also entails physically changing one writing system into another, a process that sometimes also involves a change in script. Yet this orthographic dimension has received scant attention-a neglect that Yamamoto ("Hon'yakugaku") attributes to the alphabetic bias in the translation discourse. However imperfectly, alphabetic writing represents a language's sounds, so script has been regarded in many cultures as a mere tool for textualizing the phonological structure of a language, and the significance of other aspects has been largely overlooked. 
Admittedly, the written representation does usually function as a mere interface for transmitting oral or written texts. Occasionally, however, this mediating device transcends this auxiliary function, acting as a communicative mode in its own right and affecting "broader cultural patterns of whether, why, and how translation occurs" (Denecke 206). More than just a transparent technology of writing, script is a nexus between writer and reader-a paratextual device that helps shape our interpretation of the content. Hence a change in script in the process of translation can reconfigure the meaning embodied in the script, affecting the interplay between form and content. When more than one script option is available, choices take on meaning, making translation into a different representational system challenging. Kendall (130) stresses that "The orthography is not an invisible container of the work but influences it and helps to form it. The connection between the two is so close that the use of a different orthography results in a different text."

Asian writing systems based on Chinese characters offer a useful entry point for examining how scripts shape translation practices, because these writing systems throw into sharp relief aspects that are less prominent or absent in other writing systems. Chinese logographs represent words or morphemes (not ideas directly), while also providing phonetic clues, although the script-sound correspondence is much less transparent than with alphabetic languages. The fact that "one Chinese character allows for very different Sinophone actualizations depending on linguistic and regional context" (Bachner 127) has enabled the script to be used with different Sinophone languages beyond and within mainland China's borders, such as Hakka, Taiwanese and Cantonese, as well as with sinographic languages that adopted Chinese characters, such as Japanese, classical Korean and Vietnamese and some now-obsolete Asian writing systems-even though they did not share a spoken language. Characterliterate people from different language groups within and beyond China could communicate in writing through "brush talk" or practices such as kanbun kundoku - a key script-based practice in Japan (with a Korean counterpart) that sidestepped the need for conventional translation for centuries and helped shape the Japanese conceptualization of "translation."1 The prestige of the reference culture's "scripta franca" (Denecke 209) underpinned its longstanding impact, although today the shared heritage of Chinese characters is considerably diminished.

Eventually, the Japanese, Koreans and Vietnamese devised their own scripts, albeit long used in tandem with Chinese characters. When translation from

1 See Wakabayashi, “Marginal.” 
Chinese into these sinographic languages did occur, it was facilitated by the ability to retain words written in Chinese characters, and even an approximation of the Chinese pronunciation. Although the unchanged lexical form arguably contributes to accuracy, the "character illusion" effect also makes any shifts in meaning or function more difficult to detect.

The prominent coexistence of four scripts in Japanese helps alert us to the lesser but still occasionally significant role of script in other languages, including alphabetic languages, which have some partly analogous though more limited resources that can be exploited by writers and translators. The degree of relevance of script within and across different languages and writing systems merits further investigation than it has been accorded so far in Translation Studies and related fields.

\section{Japanese: A Paradigmatic Case}

Japanese merits special attention because of the coexistence of four scriptskanji, hiragana, katakana and the Latin alphabet (rōmaji)—used for complementary purposes in a complex yet "fully functional" (Smith 214) writing system. Broadly speaking, kanji (Chinese characters) are used for content words, while hiragana are mainly used to express grammatical morphemes as well as for Japanese words without kanji and for "expressive and mimetic items" (Backhouse 222). Katakana are generally reserved for transcribing non-Chinese loanwords, visually conveying a sense of linguistic and cultural otherness. The Latin alphabet is used for "European names, citations and addresses, for many abbreviations, and increasingly for slogans and quotations" (Bringhurst 51), and also as a decoration (a phatic rather than communicative function) - so simply reproducing these expressions when translating into a language using the Latin alphabet might fail to achieve an equivalent feeling about the style. Robertson (205) comments that

As each of these [four scripts] has the theoretical ability to represent any word in the language, Japanese writers have a potential for orthographic flexibility at their disposal which is not available in other languages. This is not to say that selection of script is disorganized or capricious, but rather that creative or nonconventional uses of script represent an undeniably rich, involved, and longstanding aspect of written Japanese.

This hybridity gives rise to the question of mutual "translation" among these scripts, each of which has not only a different appearance but also a differ- 
ent "feel" (even though the pronunciation is the same). Iwahara, Hatta and Maehara (393) note that "reading experiments have suggested that when the Japanese see the Kanji word for chair, 椅子, an image of an old-fashioned strongly-built chair is usually generated, and the Katakana word for chair, イス, generates an image of a modern-elegant chair. The Hiragana chair, いす, is associated with a simple wooden chair". Kendall (127) adds that "The orthography chosen can directly affect such considerations as rhythm, puns, subtext, atmosphere, emotion, the speed at which the reader assimilates the work of art and the order in which it is assimilated." Hence translators of Japanese works need to consider the function played by a writer's script choices and how to convey this in a language with different and more limited script resources. Lurie (7) notes that "similar uses of writing are apparent in such Chinese practices as the selection of semantically appealing or pejorative characters for the phonographic transcription of non-Chinese words." ${ }^{2}$

In fact, a feature of scholarly translations of Dutch, the main European language in early modern Japan, was the emphasis on yakuji (appropriate characters to express the meaning or Dutch pronunciation), rather than selecting a suitable word (yakugo) as equivalent. Here the aspect of translation-as-writing was important, and it suggests that at least until the late nineteenth century the Japanese equated the signifier and the signified to some extent. In early modern Japan, translation was in fact sometimes conceptualized as a change in script (Clements 32) — e.g., from kanji to a mixture of kanji and hiragana — and waji (literally, Japanese characters) was one word used to refer to translation.

\section{Script as a Material Factor}

Commenting on differing attitudes towards the Chinese script, Bachner (30) notes views of Chinese characters as highlighting "a resistant materiality erased or neglected in Western theories of signification". She rightly stresses the impossibility of "distinguishing neatly" between the medium and message, given their interaction (2). Although the tangible basis of writing has often been relegated to a matter of form divorced from meaning, their inseparability highlights the need to recognize script as having the capacity to shape writing and translation.

2 A related practice in Japan is ateji (attributed characters or rebus orthographies), "the practice of substituting an ideogram with a homophone having a different meaning, to play on the visual aspects of the characters" (Suter 63). 
Emmerich ("Translating" 6o9) mentions several examples of how "form itself is translated". One example is transcription into a different script or script mixture in the same language. By contrast, interlingual translation involves a different writing system (which may or may not involve a different script). Although this change in writing system is usually a straightforward procedure, when a writer pays heed to textual physicality, translators working into another writing system need to consider whether and how to replicate this feature. Georges Perec's novel La disparition is a lipogram, a kind of constrained writing where he avoided using words containing the letter $e$, possibly as a metaphor for the disappearance of Jewish people during World War II. Shiotsuka Shūichirō's translation Enmetsu does not use the hiragana $i$ ( (a somewhat similar pronunciation to $e$ ) or hiragana ending in the sound $i$ (き・し・ち・に・ひ・み・る・り). Making $i$ disappear (nakunaru なくな る) evokes the word inakunaru いなくなる (referring to a person disappearing), linking to the metaphor of loss in Perec's text. Other kinds of formal constraints that relate to the use of a particular script (rather than its inherent nature) include anagrams, pangrams and palindromes, which raise the spectre of untranslatability. Another relatively rare case is graphological translationsubstituting letters in another language that closely resemble the appearance (not sound) of the original letters.

Another way in which form takes on significance is through repetition of graphic components. If a writer deliberately chooses Chinese characters sharing the same radical, the translator should ideally indicate this somehow so that readers can appreciate the connection. Kendall gives an example in which the effect conveyed by the repeated "tree" radical that is visually important in a particular haiku-i.e., its function as a "strong, if partially hidden, reminder of trees" (132) - is conveyed verbally by an English semantic allusion ("branches").

\section{Script as a Semiotic Factor}

Even in less extreme cases, script has generative potential as a kind of "visual grammar". How meaning can be contingent on script is particularly apparent when a choice is available, since script can "express rhetorical behaviour" such as register-e.g., emphasizing kanji rather than hiragana for "formal and polite communication" (Grabowsky 16). Kanji choice disambiguates homophones with slightly different meanings—-miru 見る (to see) vs miru 診る (to see a patient). Even with contextual help, without kanji it can be difficult to understand a hiragana word such as kikōきこう, which can be written in kanji in about 70 different ways. 
Often the choice between kanji and kana (the collective name for hiragana and katakana) is governed by convention, so contravening expectations can have rhetorical impact. In his novel Torikaeko, Ōe Kenzaburō repeatedly writes the demonstrative pronoun are (normally written in hiragana) in katakana to refer to a traumatic incident. In her translation The Changeling, Deborah Boehm renders this in all-caps as тнAт. In Japanese a katakana name might be romanized or written in kanji to convey sarcasm, or Japanese product names or business names might be romanized to catch attention. Writing Sino-Japanese words in katakana gives a more "colloquial, casual, and humorous tone" (Ezaki 199) or highlights the word, similar to italics or capitalization in English. Below the unusual impact of the katakana is rendered by a Latin phrase:

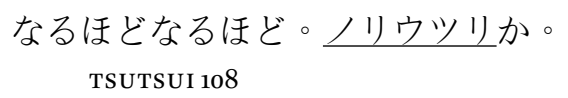

"I see, yes, I see. Mutatis mutandis." DRIVER 252

In a different context, Smith and Schmidt (67) note that writing naruhodo (I see) in katakana instead of hiragana would impart "a marked sentence intonation pattern" if spoken. In translation this might be indicated by italics or word elongation.

Regarding such choices as a matter of mere taste underestimates their rationale and impact. Exploitation of orthographic possibilities in Japanese is prompted not only by the stylistic effect or a desire to conform (or otherwise) to the official list of characters in regular use or to mass media styleguides, but also by extralinguistic factors such as the subject of the text, the genre, ${ }^{3}$ audience

3 Smith and Schmidt (59) found that the use of different Japanese scripts varies significantly by genre:

\begin{tabular}{|c|c|c|c|c|c|}
\hline & High & & & & Low \\
\hline Hiragana & comic & romance & mystery & SF & business \\
\hline Kanji & business & mystery & romance & SF & comic \\
\hline Katakana & comic & $\mathrm{SF}$ & romance & business & mystery \\
\hline
\end{tabular}

Comics and romances made significantly less use of katakana for loanwords and significantly more for features such as "emotional or evaluative elements" (66). Certain genres (e.g., newspapers) are also more likely to adhere to conventional script usage. 
age and literacy level (Smith \& Schmidt 67), and "the environment, medium, and author's intent" (Robertson 208).

The script mixture or use of non-standard characters can convey semantic, rhetorical or emotional effects-e.g., cuteness, irony, (in)formality or colloquiality, an intellectual or archaic image, or euphemism. ${ }^{4}$ Iwahara, Hatta and Maehara (394n) observe that the semantic emotional information conveyed by different types of script or print may derive from "their appearance, situations in which they are used and guidelines for use." They conducted a study of the associations of different Japanese scripts and concluded that "Kanji is associated with emotional semantic images such as active, strong, masculine, integrity, honesty, uprightness and so on, and Hiragana corresponds to semantic images such as mellow, gentle, graceful, mild, sweet and so on." (383). Kanji convey a stiff or learned (even pedantic) air, whereas hiragana give a softer, more feminine or intimate impression (suited to expressing personal thoughts and emotions). Katakana have a more austere but also foreign and modern air than hiragana. ${ }^{5}$ Writers use these differential features to achieve a desired effect. Discussing a passage in Futabatei's Ukigumo in which Bunzō says he has been sacked (ム、めん職になりました), Levy (51) comments that

While this statement could be translated into English as "I was di-dismissed," the Roman alphabet cannot approximate its particular orthographic configuration. The first sound, " $m u$," is written in katakana to emphasize its quality as a stuttering sound rather than a morpheme. Of infinitely greater significance, however, is the fact that when Bunzô does manage to blurt out the two-character compound "menshoku," it is rendered half in hiragana, as though to reflect the speaker's desperate desire to strip the word of the meaning visually fixed in its ideographic form.

In early modern Korea the ruling yangban class looked down on fiction and theater "as the expression of vulgar notions" (Suh 24), so most works in these genres were written in the vernacular Hangeul script associated with the lower classes, rather than in the higher-class mixture of Chinese characters and Hangeul. Today the use of Chinese characters in Korea has been "typically relegated to academic and ceremonial domains" (Silva 71).

4 An example is the recent trend in Japan to write shōgaisha 障害者 (a person with a disability) as shōgaisha 障がい者 to avoid the associations of gai 害 (impairment). Critics have argued that this actually accentuates these negative associations and constitutes excessive "political correctness".

5 See Robertson (207) for a table showing the associations ascribed to hiragana, katakana, kanji and rōmaji. 
In his novel 1084 Murakami Haruki used a hiragana-katakana mixture to indicate a character's dyslexia. In her Polish translation, Zielinska-Elliott wrote this dialogue in lowercase even at the start of sentences, while the Swedish translator divided all the words "into syllables using hyphens in order to stress the monotony of Fukaeri's diction" (Zielinksa-Elliott \& Holm 13). The Russian translator used italics with hyphens between the words. Although I do not have the competence in these languages to evaluate the effectiveness of these techniques, they at least mark the non-normative nature of this character's speech.

\section{少女はシホンシュギ（時にはブッシツシュギという言葉が使われ \\ る）が何であるかを知らない。 MURAKAMI 171}

The girl does not know what theymean by "cap-i-tal-izum" (or the otherword they sometimes use, "ma-teer-ee-al-izum") ...

RUBIN $53^{2}$

When translating from Japanese, these semantic aspects of script choice need to be conveyed by some means. Devices such as fonts, italics, upper or lower case, and non-standard spelling can sometimes offer partial solutions to the translation challenges presented by semiotic uses of Japanese scripts, although they cannot always fully convey the meaning, as demonstrated in the Ukigumo example. For instance, Robertson (206) notes that

Unlike with font, the use of multiple scripts is an important aspect of normal Japanese and something all literate Japanese are already familiar with. [...] Furthermore, the impressions native Japanese speakers have of each script can function in addition to any they may have of a particular font, and are substantially deeper and more detailed.

Manipulation of font size is another resource available to translators, as is the use of a font combination, which "in the West gives the text a distinctly modern feel" (Kendall 135).

Conversely, translators working into Japanese can use script for effect by exploring possibilities not available to those working into monoscriptal languages. When translating Anaïs Nin's Winter of Artifice as Jinkō no fuyu, Kimura Junko rendered italicized passages describing the heroine's emotions in hiragana and used kanji for difficult words or abstract expressions of Latin origin so as to give "a detached and formal impression" (Kimura 214). She notes that 
kanji convey an "exotic mood", a technique often used in translations of European modernist poetry.

In addition to script choice, the Japanese writing system includes symbols "to indicate variations in vowel length, especially nonphonemic but emotive variations [...] All these devices express linguistic (phonetic) or paralinguistic information conveyed in spoken language, but not represented in conventional writing" (Tranter 141). For example, a half-sized kana vowel can be used for emphasis一おわりましたかあ.Gottlieb (397) comments that such usages are typically aimed at conveying informality or cuteness.

\section{Script as a Creative Factor}

Some have criticized Chinese characters as an obstacle to creativity, yet their versatility offers inventive potential in original and translated works. In Japanese, kanji can be used "for meaning, for sound when read in Chinese, and for sound when read in Japanese" (Denecke 207), enabling "a literary playfulness impossible with alphabetic languages where graphs are more closely linked to pronunciation" (208). Maynard (148) gives the example of a pun involving 骨折, which can be read in its Sino-Japanese pronunciation kossetsu (broken bone) or its Japanese pronunciation hone-ori (effort).

Japan has a long tradition of orthographic puns, exploiting the tension between form and content. The fact that kanji express sound and meaning enables wordplay where a kanji is replaced with a homophone. Kanji's visual aspects come to the fore in advertising, often through playful use of the shape or parts of characters-e.g., drawing on the literal meanings of disassembled kanji parts. In a hair restoration lotion advertisement, the character kami 髪 (hair) is deconstructed into its three main components-長 (long), 乡 (the radical for hair) and 友 (friend) — so as to play on the idea that using this lotion will make one's hair a longlasting friend (see YouTube). Similar script literalization is impossible in a non-sinographic language (although graphic art might sometimes convey a comparable effect), so rewriting or creation of a new advertisement altogether is necessary. Writers and translators also sometimes use hiragana to allow different semantic possibilities to come into play. The fact that alternative homographs might "hover" over a particular phonetic reading (Kendall 137) adds interpretive richness.

Pseudo-characters use "ideographic principles to craft new characters whose meaning - though not part of the lexicalized vocabulary-is easy to guess" (Bachner 176). An extreme example of such creativity (one where the individual pseudo-characters have no decipherable meaning) is Xu Bing's literary art 
work titled Tianshu or A Book from the Sky. This involved inventing over 4,00o pseudo-characters, resulting in a text whose intent is "to subvert the institution of writing" (Lee "Visuality" 47). Surprisingly, this otherwise meaningless text has been translated in part by Bruno (2012), who invented an alien-yetfamiliar pseudo-English by using such devices as misspelled words, non-words and falsely derived compounds to "reproduce the overall aesthetic force" (Lee "Visuality" 50). She also used Old English typeface and the layout of old institutionalized texts and imitated the "decoration in ancient, canonical English manuscripts" (Lee Experimental 110). Lee describes Bruno's work as an intersemiotic translation "employing verbal, visual, and paratextual cues to reproduce the overall aesthetic effect". Elsewhere, however, Lee points out that it fails to replicate the text's cultural critique and intersemiotic tension because it is decontextualized ("Visuality" 51).

\section{Script as an Aesthetic and Visual Factor}

Script also embodies aesthetic elements that constitute an aspect of visual communication, where form and complexity (or simplicity) signify. The most obvious manifestation is Chinese calligraphy, a tradition that "values scriptural beauty, sometimes at the expense of discernible meaning” (Bachner 170).

The visual aspects can also be crucial in literature. Meaning can be generated by formal qualities such as "the shape and arrangement of the script used, the size of letters, the legibility and readability of the inscription" (Eastmond 3). In turn, script-related choices affect readability and the aesthetic effect. Kanji variation fulfils a poetic function (Tranter 146), while hiragana are regarded as more aesthetically pleasing than katakana. Hence translators might need to take into account not just the appeal to the reader's ear but also the visual appeal, so that "onlookers" act as viewers, not just readers (Eastmond 3).

One aspect of how visual form contributes to meaning-making is the physical styles of writing a script. Styles of script constitute a secondary language that encodes a text with social significance beyond the graphemic and lexical values of the letters. Stanley Morison has shown that the styles of script and letter design in the history of writing were functions of political and institutional authority. The type of script in which a text appears thus provides an irreducible first context of reception and interpretation for a text (Irvine 383).

Chinese calligraphy has five basic styles: "bold and elegant" seal script; "dignified and serious" clerical script; "formal and controlled" standard script; "graceful and polished" running script; and "fluid, individualistic" grass script (Stevens 247). When a handwritten script style or a typeface (the far more 
common form encountered by translators today) departs from the norm, translators need to consider evoking a similar "personality". For example, Garamond embodies a "classic and easy-going beauty", while Monotype Corsiva mimics the effect of handwritten text and is suitable for conveying heartfelt sentiments (see Purdue owL). The Kocho kanji typeface represents "the aesthetic values seen in Bodoni, its Western counterpart" (Takagi 13). Noting the neglect of such aspects by translation scholars, O'Sullivan (4) points out, for example, that sans serif fonts are usually preferred for subtitles.

It is challenging to emulate in an alphabet language the balance or interplay among kanji and kana on a page-what Mishima Yukio referred to as "the beauty of the disposition of the 'dark' and 'light'" (quoted in Seidensticker 30). This contrast also contributes to the impression of a text's density, difficulty or fluidity. Kana interspersed among kanji function "almost as breathing spaces that tie the whole together. In short, the kana serve as $m a$ ""intervening empty space" (Arata 59), which is an underlying aesthetic principle in Japan. Shelton and Okayama (169) note that in Tanizaki Jun'ichirō's short story "Mōmoku monogatari", "For the text depicting the blind man's movement and sensing of the light, the sparser and more abstract kana is used: but where objects are encountered and touched to reveal shape, texture and meaning, kanji appears on the page." They conclude that Tanizaki produced "an aesthetic-cum-pictorial reinforcement of the text" (170) - although the English translation does not replicate this. Hibbett (40) has commented on the difficulties he faced in translating Tanizaki's novel Kagi, where the secret diaries were written in "square katakana for the man's diary and flowing hiragana for the woman's." Hibbett's partial solution in The Key was to adopt a feminine style of writing for the woman's diary.

A Japanese saying describes translation as an act of converting horizontally written text into vertical text (or vice versa). Although translation involves far more than the merely mechanical act implied by this saying, even text direction does have "meaning" when a choice is available. Kendall (136) notes the multidirectional flexibility of Japanese writing — "horizontally from left to right", "horizontally from right to left (rarer these days, but still used, for example, on goods vehicles)", and "vertically from right to left". The direction influences the aesthetic impression, so "a Japanese reader is likely to be more aware than a reader accustomed to a Latinate script, not only of how a text is organized, but of how it is not organized; of the alternatives not selected" (137). Distinctions deriving from text directionality are, however, usually elided in translation. 


\section{Script in Poetry}

Visuality has particular appeal in poetry, making translation into a different linguistic form even more challenging. Most famous in this respect is concrete poetry, which involves "activating the graphic, material expressivity of language" over and above linguistic signification (Bachner 80).

A change in script (e.g., from hiragana to a mixture of kanji and kana) can alter the interpretation or impression of a poem. In Hagiwara Sakutarō's freeverse "Ryojō," France was written as $ふ ら ら ん す$ to indicate his longing for France (rather than referring to the geopolitical entity, usually written in katakana). When Arthur Binard translated this as "On the Way", he rendered the impact by deciding to "infuse the entire poem with the feeling of France representing the longing to go someplace far away with a lot of imaginative power for the poet" (Takemori 42). In a poem by Minashita Kiryū, katakana are arbitrarily inserted within hiragana words. In Sawako Nakayasu's translation "Border z / Delete, and Rewrite", capital letters are used in the middle of English words to impart a similar unsettling effect.

\section{Script as an Exoticizing Factor}

Script can accentuate the foreignness of elements (e.g., borrowed words, or speech by non-native Japanese). The aura surrounding katakana loanwords contributes to a foreignizing translation (not necessarily a bad thing). This can hinder "real integration" (Suter 65) or, conversely, pave the way for domesticating these foreign elements. Bachner (94) identifies two features of Chinese characters when viewed from outside: "as pure ornament or cipher of cultural difference". Unconventional script use has a similar defamiliarizing effect. Traces of the allure of European scripts in East Asia linger in the use of often-nonsensical alphabet expressions, here suggesting Western provenance or "coolness".

Mizumura Minae's novel Shishōsetsu from left to right has English expressions and sentences intermingled with the Japanese on nearly every page, integral to this story of two Japanese sisters in New York. The worlds expressed by the novel's bilinguality would be lost if unified into English in translation. This linguistic interplay in orthographic (as well as lexical and syntactic) form represents a meaningful or motivated strangeness that makes demands on Japanese readers. In his translation An "I"Novel, from Left to Right, James E. Lipson sought to achieve something of a similar impact by using italics to indicate the original English. 


\section{Script's Ideological Freight}

Ricci (80) argues that "Scripts, often viewed as technical devices in the service of meaning, are in fact sites of power: religious, social, and political." This raises questions of their function (e.g., to unite or divide) and who is entitled to use them. Scripts can be implicated in (de)colonization or the introduction of a foreign religion; discourses of hindering or promoting modernization; or use by a particular group, gender or generation. They can be used-or bannedon various ideological grounds, and a script's foreign origin can be respected or distrusted. In Japan, kanji's links with China imparted great cachet. Chinese civilization was regarded with such esteem that some kana texts were rescripted into Chinese characters. Ideological uses of script are not, however, confined to ideographic languages, as witnessed by the choice between Cyrillic or Latin scripts to write different Slavic languages.

Although script can act as a badge of cultural (as distinct from national) identity, Chineseness is not necessarily represented by Chinese characters, even within China. ${ }^{6}$ For those on the Sinosphere's periphery, moreover, the script has "nationalistic overtones" (Tsu 211). The lack of fit between a "central" script and regional vernaculars can cause problems, including a sense of ambivalence about (and technical difficulties in) writing or translating in a dominant script that does not encapsulate local linguistic and cultural identity.

Scripts can carry a symbolic or mystical value separate from their content or readability. Some, particularly archaic scripts, have a power deriving precisely from their non-readability. Stevens (244-245) notes that "even when the sutras were translated into Chinese, mantra (esoteric formulas) were reproduced in the Siddham script", which was "venerated for its beauty and magic". The ties between a religion and a script are also evident in how, although Buddhist classics were published in Hangeul soon after its invention in 1443, Buddhism was too embedded in Chinese literary culture for the Hangeul versions to be handed down (Kim 44). Christianity, however, entered Korea "exclusively and initially through Bibles translated in Korean using hangeul-only orthography" (45). Missionaries' encouragement of Hangeul around the turn of the twentieth century was partly driven by a desire "to turn Korea away from Confucian China" (Silva 58). Conversely, ties between a particular script and missionaries can act as a disincentive to use that script. In the early decades of the twentieth

6 Apart from Pinyin, the Arabic script is used for writing the Uyghur language in Western China, and the Cyrillic and Latin scripts are also used in China. 
century translations of the New Testament were printed in the Pollard script developed for writing Miao, the language of a Chinese ethnic minority, but after the adoption of Pinyin for writing standard Chinese, the Pollard script lost status, partly because of its missionary ties.

Some scripts have been used solely or predominantly by a particular gender. ${ }^{7}$ In southern China the Nüshu script was used exclusively among women in a few villages in Hunan province. The last original writer of the script died in 2004, but the Chinese government has initiated preservation efforts. Liu (241) argues that women used this script to "construct meaning, experience autonomy, and acknowledge the androcentric impositions made upon them". Nüshu writings have been translated into Chinese, but without paratextual contextualization in the form of a preface, for example, translations cannot convey this script's gendered associations.

\section{Changing or Abandoning a Script}

Scripts are "embedded in particular cultures and histories" (Ricci 170), so adopting a different script is "akin to translation in the guise of transliteration" (180), since it involves new "modes of expression". It also makes it difficult to access a society's heritage; such distancing from the past or others is sometimes the very intention. In 1446 King Sejong promulgated Hangeul, rejecting Chinese characters as unsuitable for Korean. Adopting a script that more closely reflects vernacular language has the potential to offer "alternative avenues for expression closer to native feelings" (Fogel 501), but there was considerable resistance, particularly among the Korean elite, partly because of the large body of existing texts in Chinese characters. Even after Hangeul finally became the national script in 1894, Chinese writing remained dominant for a few decades. Eventually, however, existing works became inaccessible to untrained readers, therefore requiring translation or at least transcription.

7 Different genders (and generations) of Japanese writers tend to favor one script over another. The study by Smith and Schmidt (50) identified the following script stereotypes:

Writer/Reader Features

$\begin{array}{ll}\text { Kanji } & \text { male, middle-aged and older } \\ \text { Hiragana } & \text { female, young } \\ \text { Katakana } & \text { young, especially male } \\ \text { Rômaji } & \text { young, especially female }\end{array}$


Some people regarded Japan's complex writing system as an obstacle to modernization and a sign of the language's inferiority. The postwar Occupation witnessed proposals to ban kanji in favor of katakana or to adopt the Latin alphabet, on the grounds that it would foster a democratic spirit and international understanding. Yet kanji's productive capacities have allowed translators to coin words as equivalents for imported concepts, making the lexicon more suitable for expressing modernity.

Translation and contact with foreign languages can themselves sometimes lead to a changed textual environment. Around 1686 new writing systems (the Soyombo alphabet and the horizontal square script) appeared in Mongolia, "intended in part to enable better translations of the Buddhist religious texts, and to give a more accurate rendering of Tibetan and Sanskrit words of liturgical importance" (Grivelet 76).

Older writing conventions convey an archaic air. Historical kana usage such as 乙ふ (pronounced $c h \bar{o}$, not tefu) and old-fashioned kanji (e.g., 國) evoke a bygone era. Old texts were written in the language of their times, which suggests using current language in a translation, particularly if it is simply for informational purposes. Nevertheless, this can sound anachronistic, and old Japanese writing no longer seems contemporary to modern Japanese readers. The use of old orthography in a present-day text has a particular rhetorical effect. Strategies for translating antiquated diction as signified by script include using archaic spelling (e.g., childe); an artificial hybrid that imparts a patina of age but is not off-putting to contemporary readers; a form that is "modern enough to be read without difficulty but unmarked for modernity" (Robinson 115); a description (e.g. Using an old-fashioned turn of phrase, ...) - or contemporary language. The decision depends on the type of text and the intended purpose of the translation.

\section{Glosses and Metalinguistic References}

Chartier (ix) stresses the need to pay attention to the "technical, visual, and physical devices that organize the reading of writing." One such distinctive Japanese practice is the rubi glosses embedded in small-sized font alongside words, usually in a different script. Readers read the contrapuntal representations (two pronunciations and two layers of meaning) more or less simultaneously. Irvine (392) stresses that "text and gloss are mutually dependent, and the gloss is quite clearly presented as a text with its own pre-assigned space on the page, a genre with its own textual status." Kamei (70) argues that the act of adding rubi can itself be regarded as translation. The amalgam's result- 
ing polyphony and polysemy, as well as the defamiliarizing effect are, however, virtually impossible to reproduce in a single word in another language. Tranter (139) gives an example of rubi used to show "the speaker's attitude to the referent" and describes this as "a graphic way of reproducing tone of voice" (140), while Suter (73) comments that such glosses raise "the reader's awareness of the existence of different linguistic realities and the textual nature of the text itself".8

Expressions that refer to the orthography itself present a challenge for translators working into a different script. The bilingual writer Tawada Yōko seeks to create new literature by focusing on script and sounds:

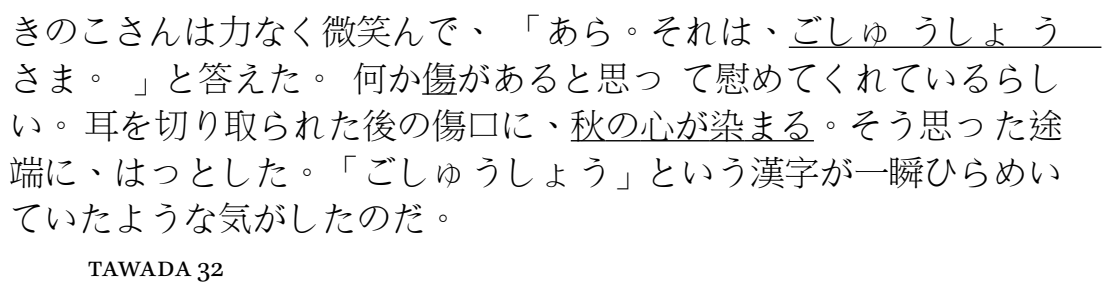

Kinoko-san smiled weakly and said, "Oh, my dear. How lamendacious, to lose your ear."

SELDEN 77

Here the extended play on the graphic elements of the word shūshō 愁傷 (condolences) is replaced by the made-up word lamendacious, in line with Kinoko's habit of mis-rendering words. Kaindl (90-91) suggests that for Tawada "it is not the word, but the script and the character that represent the actual translation unit and the actual translation problem".

If the item is not of importance, translators can simply add a phrase such as in Japanese, or a reference to the two characters of a word could be replaced with a reference to the six letters of the equivalent. In Japanese the practice of three people sleeping side by side is referred to as sleeping in the shape of the character for "river" (Щ), and this was handled differently by these translators:

... we all slept in a row. Holding hands, like the three strokes of the character for "river."

EMMERICH, The Lake 169

8 See Wakabayashi (“Translating") for further discussion. 
... all snuggled up on the floor together like the Roman numeral III SHIMOKAWA 55

At other times it might be preferable to mask the reference's script-based nature if that would confuse readers or be of no interest or relevance:

…株の「か、の字も知らなかつた。

TAGUCHI 72

I didn't know the first thing about stocks ... (literally, the ka of kabu [stocks])

\section{Conclusion}

I acknowledge that in many cases script is indeed largely a neutral vehicle for meaning, and we should be careful not to fetishize "a script essence that will survive and resist translation between languages and cultures as well as between different media" (Bachner 206). Nevertheless, script does sometimes become a mediating force in its own right, and these cases have been underexamined in Translation Studies. Kendall (143) declares that

The nature of translation as a creative act is made even clearer when it occurs ... from one orthography to another ... It is not possible to find equivalents when dealing with such diverse orthographies. There are none. The translators have to create in new spaces and form a text that is suitable for them.

Script-based features of particular relevance in a source text call for creativity and a range of compensatory techniques. Although the effect might not be exactly the same as that of the original feature, translation inevitably entails some degree of difference. The techniques identified in the examples mentioned here include visual devices such as decorative and graphic art, as well as visual $\rightarrow$ verbal intersemiotic translation. They also include typographical devices-e.g., fonts and typefaces; layout; unconventional use of upper or lower case; italics; word elongation; hyphenation. Another technique involves lexical devices-e.g., (mis)spelling or archaic spelling; difficult or abstract expressions (e.g., Latin or Latin-derived words rather than Anglo-Saxon equivalents); non-words; falsely derived compounds. Other techniques include the use of gendered style, tone of voice, paratextual cues, explanatory descriptions, 
artificial hybrid language, and a holistic infusion of the effect — or a combination of two or more of the above techniques, which by no means exhaust the possibilities. Although these techniques might fail to make readers aware of the exact nature of the scriptness of the source text, they succeed in revealing the marked (unconventional) nature of the pertinent passages. The converse of these techniques can at times be used when translators working into sinographic languages seek to exploit the possibilities of script.

The relevance of script in translation involving sinographic languages applies in varying degrees to other languages where script choices are available or there has been a change in script, and even to monoscriptal traditions, where translators could benefit from paying greater attention not only to a writer's constrained orthographical choices, for example, but also to the related areas of visual and typographical choices. Script is of particular interest in languages which, often for political reasons, are written in more than one script, such as Sanskrit (written in Devanagari and many regional scripts), Malay (Arabic and Latin) and Tajik in Central Asia (Arabic and Cyrillic). When nearidentical languages use different writing systems (e.g., Serbian and Croatian, Hindi and Urdu), "translation" largely equates with script change-yet with broad implications. Kothari (97) asks

How do we understand translation when what appears as 'Hindi' by some gets labelled as 'Urdu' elsewhere? Is that the same 'thing' but with different labels and therefore not in need of translation? On the other hand, Urdu and Hindi are polarized along political ideologies and seek mediation that foregrounds the common roots, an act made possible by both translation and interpretation.

How do we theorize language, script and translation in such contexts?

\section{Works Cited}

Arata, Isozaki. "Acceptance and Creation: The Aesthetic of an Island Nation." Japan Echo 34: 4 (2007), 58-62.

Bachner, Andrea. Beyond Sinology: Chinese Writing and the Scripts of Culture. New York: Columbia UP, 2014.

Backhouse, A.E. "Aspects of the Graphological Structure of Japanese." Visible Language 18: 3 (1984), 220-228.

Bringhurst, Robert. The Solid Form of Language. Kentville, N.s.: Gaspereau Press, 2004. 
Bruno, Cosima. "Words by the Look: Issues in Translating Chinese Visual Poetry." China and Its Others: Knowledge Transfer through Translation, 1829-2010. Amsterdam, New York, NY: Rodopi, 2012, 245-276.

Chartier, Roger. The Order of Books: Readers, Authors, and Libraries in Europe between the Fourteenth and Eighteenth Centuries. Stanford, California: Stanford UP, 1994.

Clements, Rebekah. A Cultural History of Translation in Early Modern Japan. Cambridge: Cambridge UP, 2015.

Denecke, Wiebke. "Worlds Without Translation: Traditional East Asia and the Power of Character Scripts." A Companion to Translation Studies, ed. Sandra Bermann and Catherine Porter. Chichester, West Sussex: Wiley Blackwell, 2014, 204-216.

Driver, Andrew. Salmonella Men on Planet Porno. New York: Pantheon Books, 2008.

Eastmond, Antony. Viewing Inscriptions in the Late Antique and Medieval World. New York, NY: Cambridge UP, 2015.

Emmerich, Michael. The Lake. Brooklyn, N.Y.: Melville House, 2011.

Emmerich, Michael. "Translating Japanese into Japanese: Bibliographic Translation from Woodblock to Moveable Type." A Companion to Translation Studies, ed. Sandra Bermann and Catherine Porter. Hoboken: Wiley-Blackwell, 2014, 599-611.

Ezaki, Motoko. "Strategic Deviations: The Role of Kanji in Contemporary Japanese." Japanese Language and Literature 44: 2 (2010), 179-212.

Fogel, Joshua. "Nationalism, the Rise of the Verrnacular, and the Conceptualization of Modernization in East Asian Comparative Perspective." Between China and Japan: The Writings of Joshua Fogel. Leiden: Brill, 2015, 496-506.

Gottlieb, Nanette. "Playing with Language in E-Japan: Old Wine in New Bottles." Japanese Studies 30: 3 (2010), 393-407.

Grabowsky, Volker. Southeast Asian Historiography: Unravelling the Myths: Essays in Honour of Barend Jan Terwiel. Bangkok: River Books, 2011.

Grivelet, Stéphane. "Digraphia in Mongolia." International Journal of the Sociology of Language $15^{0}$ (2001), 75-94.

Hibbett, Howard. "Howard Hibbett on Tanizaki Jun'ichiro." Words, Ideas, and Ambiguities: Four Perspectives on Translating from the Japanese, ed. Donald Richie. Chicago: Imprint Publications, 2000, 35-50.

Irvine, Martin. The Making of Textual Culture: "Grammatica" and Literary Theory 350110o. Cambridge [England] and New York: Cambridge UP, 1994.

Iwahara, Akihiko, Takeshi Hatta, and Aiko Maehara. "The Effects of a Sense of Compatibility between Type of Script and Word in Written Japanese." Reading and Writing 16: 4 (2003), 377-397.

Kaindl, Klaus. "Of Dragons and Translators: Foreignness as a Principle of Life: Yoko Tawada's 'St. George and the Translator.'” Transfiction. Research into the Realities of Translation Fiction, ed. Klaus Kaindl and Karlhienz Spitzl. Amsterdam and Philadelphia: Benjamins, 2014, 87-101. 
Kamei, Hideo. "Honyaku to bōkun-'Shōsetsu Shinzui' kenkyū (5)" ("Translation and Diacritics: A Study of 'The Essence of the Novel'). Hokudai bungakubu kiyō 40: 1 (1991), 65-118.

Kendall, Judy. "Translation and the Challenge of Orthography." Translation and Creativity: Perspectives on Creative Writing and Translation Studies, ed. Manuela Perteghella and Eugenia Loffredo. London and New York: Continuum, 2006, 127-144.

Kim, Jeongsu. The History and Future of Hangeul: Korean's Indigenous Script. Kent, U K: Global Oriental, 2005.

Kimura, Junko. "Between Two Languages: The Translation and Reception of Anaïs Nin in Japan." Anaïs Nin: Literary Perspectives, ed. S. Nalbantian. New York: St Martin's, 1997, 211-220.

Kothari, Rita. "Response." Translation Studies 7: 1 (2014), 96-97.

Lee, Tong King. "Visuality and Translation in Contemporary Chinese Literary Art: Xu Bing's A Book from the Sky and A Book from the Ground." Asia Pacific Translation and Intercultural Studies 1: 1 (2014), 43-62.

Lee, Tong-King. Experimental Chinese Literature: Translation, Technology, Poetics. Leiden and Boston: Brill, 2015 .

Levy, Indra. "The Anxiety of Translation: Interlingual Seduction and Betrayal in Futabatei Shimei's Ukigumo." Proceedings of the Association for Japanese Literary Studies vol. 7, 2001, 47-6o.

Liu, Fei-Wen. "Literacy, Gender, and Class: Nüshu and Sisterhood Communities in Southern Rural Hunan." Nan Nü 6: 2 (2004), 277-278.

Lurie, David B. Realms of Literacy: Early Japan and the History of Writing. Cambridge, Mass.: Harvard University Asia Center, 2011.

Maynard, Senko K. Linguistic Creativity in Japanese Discourse: Exploring the Multiplicity of Self, Perspective, and Voice. Amsterdam and Philadelphia: Benjamins, 2007.

Murakami, Haruki. 1Q84. Book 2. Tokyo: Shinchōsha, 2009.

O'Sullivan, Carol. "Introduction: Multimodality as Challenge and Resource for Translation." Journal of Specialised Translation 20 (2013), 2-14.

Purdue OwL, the. "Using Fonts with Purpose." Web. 13 Sep. 2015.

Ricci, Ronit. Islam Translated: Literature, Conversion, and the Arabic Cosmopolis of South and Southeast Asia. Chicago: University of Chicago Press, 2011.

Robertson, Wes. "Orthography, Foreigners, and Fluency: Indexicality and Script Selection in Japanese Manga." Japanese Studies 35: 2 (2015), 205-222.

Robinson, Douglas. "Intertemporal Translation." Routledge Encyclopedia of Translation Studies. London and New York: Routledge, 1998, 114-116.

Seidensticker, Edward. "Edwin Seidensticker on Nagai Kafu and Kawabata Yasunari." Words, Ideas, and Ambiguities: Four Perspectives on Translating from the Japanese, ed. Donald Richie. Chicago: Imprint, 2000, 19-34.

Selden, Yumi. "Spores." Where Europe Begins. New York: New Directions, 2002, 67-84. 
Shelton, Barrie, and Emiko Okayama. "Between Script and Pictures in Japan." Visible Language 40: 2 (2006), 155-176.

Shimokawa, Emi. Twinkle Twinkle. New York: Vertical, 2003.

Silva, David J. "Missionary Contributions toward the Revaluation of Hangeul in Late Nineteenth-Century Korea." International Journal of the Sociology of Language 192 (2008), 57-74.

Smith, Janet S. (Shibamoto). “Japanese Writing." The World's Writing Systems, ed. Peter T. Daniels and William Bright. Oxford: Oxford UP, 1996, 209-217.

Smith, Janet S. and David Schmidt. "Variability in Written Japanese: Towards a Sociolinguistics of Script Choice." Visible Language 30: 1 (1996), 46-71.

Stevens, John. "Asian Calligraphy." The World's Writing Systems, ed. Peter T. Daniels and William Bright. Oxford: Oxford UP, 1996, 244-251.

Suh, Serk-Bae. Treacherous Translation: Culture, Nationalism, and Colonialism in Korea and Japan from the 1910s to the 196os. Berkeley, Los Angeles, London: University of California Press, 2013.

Suter, Rebecca. The Japanization of Modernity: Murakami Haruki Between Japan and the United States. Cambridge, MA, London: Harvard University Asia Center, 2008.

Taguchi, Tomotaka. Dōshitemo tsuzukerarenai hito no warui shūkan 45 (Fourty-five Bad Habits of those Who Can't Continue). Tokyo: Magajin Hausu, 2012.

Takagi, Mariko. "Kanji Graphy: Visual Translation between Latin Letters and Japanese Characters." LetterSeed 11 (2015), 1-15.

Takemori, Ginny Tapley. "Poetry for All Senses: SWET Summer Party at Rikugien." sWET Newsletter 121 (2008), 40-50.

Tawada, Yōko. "Hōshi." Hikari to zerachin no Raipuchihhi (Leipzig in Light and Gelatin). Tokyo: Kōdansha, 2000, 23-40.

Tranter, Nicolas. "Nonconventional Script Choice in Japan." International Journal of the Sociology of Language 192 (2008), 133-151.

Tsu, Jing. Sound and Script in Chinese Diaspora. Cambridge, Mass.: Harvard U P, 2010.

Tsutsui, Yasutaka. Poruno wakusei no sarumonera ningen (The Salmonella People on the Pornographic Planet). Tokyo: Shinchōsha, 2005.

Wakabayashi, Judy. "Marginal Forms of Translation in Japan: Variations from the Norm." Unity in Diversity? Current Trends in Translation Studies, ed. Lynne Bowker, Michael Cronin, Dorothy Kenny and Jennifer Pearson. Manchester: St. Jerome, 1998, 57-63.

Wakabayashi, Judy. "Translating in a Forked Tongue: Interlinear Marginalia as a Creative Heteroglossic Device in Japanese Translations." Translation and Interpreting Studies 1: 2 (2006), 3-41.

Yamamoto, Mayumi. “Hon'yakugaku no kokoromi: shiika, rekishi, shūkyō-teki gainen no hon'yaku o megutte" ("Challenges of Translation Studies: Translations of Poetic, Historical, and Religious Terms"). Ibunka kenkyū 2 (2008), 1-14.

YouTube. “1978/80 第一製薬 カロヤン.” Web. 20 March 2016. 
Zielinksa-Elliott, Anna, and Mette Holm. "Two Moons Over Europe: Translating Haruki Murakami's 1Q84." The AALITRA Review: A Journal of Literary Translation 7 (2013), $5^{-}$ 19. 